\title{
Preliminary Metabolomic Study of Urine Samples in Patients Affected by Renal Clear Cell Cancer by GC-MS
}

\author{
Massimo Madonia ${ }^{1}$, Antonio Murgia ${ }^{2,3}$, Gianmarco Garau ${ }^{1}$, Bruno Bussa ${ }^{1}$, Pierluigi Caboni ${ }^{2, ~ *}$ \\ ${ }^{1}$ Department of Surgical, Microsurgical and Medical Sciences, University of Sassari, Sassari, Italy \\ ${ }^{2}$ Department of Life and Environmental Sciences, University of Cagliari, Cagliari, Italy \\ ${ }^{3}$ Department of Biochemistry and Cambridge Systems Biology Centre, University of Cambridge, Cambridge, UK \\ Email address: \\ caboni@unica.it(P. Caboni) \\ ${ }^{*}$ Corresponding author
}

\section{To cite this article:}

Massimo Madonia, Antonio Murgia, Gianmarco Garau, Bruno Bussa, Pierluigi Caboni. Preliminary Metabolomic Study of Urine Samples in Patients Affected by Renal Clear Cell Cancer by GC-MS. International Journal of Clinical Urology. Vol. 2, No. 1, 2018, pp. 1-5. doi: 10.11648/j.ijcu.20180201.11

Received: May 17, 2018; Accepted: June 12, 2018; Published: July 6, 2018

\begin{abstract}
Renal cell carcinoma (RCC) represent 2-3\% of all cancers. Currently, there are no invasive screening tests that could help to find diagnosis and possible follow up in clinical practice. Most renal tumors are diagnosed by abdominal ultrasound (US) or contrast-enhanced (CT) performed for other medical reasons. In this work, the metabolite profile of urine of RCC samples, has been studied by gas chromatography coupled to mass spectrometry (GC-MS) and multivariate statistical data analysis. By the same means, differences between pathological and control samples were investigated. Results of discriminant analysis were studied with the aim to find possible relevant metabolites for each class. Palmitic acid, malic acid, allo-inositol, oleic acid and aspartic acid were up-regulated in pathological samples while psicose was down-regulated.
\end{abstract}

Keywords: Inositol, Aspartic Acid, GC-MS, Renal Cell Cancer

\section{Introduction}

Among the amount of tumor types, RCC represents the 2$3 \%$ of all cancers [1], holding the highest incidence in Western countries [2]. RCC includes a broad spectrum of histopathological entities described in the 2004 World Health Organization classification [3] and modified by the International Society of Urological Pathology (ISUP) (Vancouver Classification) [4] in which the most common member is clear cell RCC (ccRCC) [5]. Several renal masses remain asymptomatic until the late disease stages. The $50 \%$ of RCCs are detected accidentally due to non-specific symptoms and for the totally absence of non-invasive tests $[6,7]$. Most renal tumors are diagnosed by abdominal US or $\mathrm{CT}$, regularly performed for further disease examination [7]. Currently, there are no blood or urine screening tests that can help in the diagnosis of this pathology. Numerous molecular markers, such as carbonic anhydrase IX (CaIX), vascular endothelial growth factor (VEGF), hypoxia-inducible factor (HIF), Ki67 (proliferation), p53, p21 [8], PTEN (phosphatase and tensin homolog) (cell cycle), E-cadherin, C-reactive protein (CRP), osteopontin [9], CD44 (cell adhesion) [10, 11], CXCR4 [12], and other cell cycle and proliferative markers $[13,14]$ have been investigated. Unfortunately, these markers were not improved as possible prognostic biomarkers. Moreover, the therapy is essentially surgical at the early stage. If RCC has spread outside of the kidneys, often into the lymph nodes, the lungs or the main vein of the kidney, then multiple therapies are used including surgery and medications. RCC is resistant to chemotherapy and radiotherapy in most cases, but it does respond well to immunotherapy with interleukin-2 or interferon-alpha, biologic, or targeted therapy. In all RCC types, prognosis worsens with stage and histopathological grade. The 5-year overall survival percentage (OS) for all types of RCC is $49 \%$, which has improved since 2006 probably due to an increase in incidentally detected RCCs and because of the introduction of tyrosine kinase inhibitor (TKI) [15].

Metabolomics, one of the latest omics sciences, could be a useful approach to understand pathogenic mechanism in human being. In fact, this technique explores the profile of different biological matrices through the study of 
metabolites. In a biological system, such as urinary samples, a metabolite up-regulation could share information concerning the physiological and functional status of such system. Metabolomics is based on the use of different hyphenated analytical techniques, such as mass spectrometry as well as nuclear magnetic resonance spectroscopy (NMR). These techniques are often associated to a multivariate statistical analysis with the aim to extract useful information from complex models [16-18] and thus understanding mechanism of action. These techniques are related to a multivariate statistical analysis useful to extract information from complex matrices [19] and to understand possible mechanism of action. In this work, we used a metabolomics approach based on GC-MS coupled with multivariate data analysis with the aim to highlight possible discriminant metabolites that could help in both diagnosis of RCC and understanding the metabolic pathways implicated in this pathology.

\section{Materials and Methods}

\subsection{Subjects}

This study was carried out on urine samples collected from patients affected by clear cell renal carcinomas, admitted to the Urological Clinic of the University of Sassari (Sassari, Italy). This pathological pool consisted of six males and seven females with an average of age of 57 and 65 respectively, not presenting any comorbidity. Furthermore, a healthy control group comprising of six women with a mean age of 62 years and nine males with a mean age of 56 years was analyzed. As well as for the patients, the absence of any illnesses was verified, as well as for tmmors. Written informed consent was obtained from all participants before enrolment in the study.

\subsection{Chemicals}

All the chemicals used in this study were of analytical grade. Derivatized 2, 2, 3, 3-d4-succinic acid was used as internal standard, and pyridine and hexane were used as solvent (Sigma Aldrich, Milano, Italy). Methoxyamine hydrochloride, N, O-bis (trimethylsilyl)trifluoroacetamide, trimethylchlorosilane (BSTFA+TMCS), and all the analytical standards were purchased from Sigma (St. Louis, MO, USA).

\subsection{Urine Samples Collection and Preparation}

Urine samples $(2-3 \mathrm{~mL})$ were collected into a $15 \mathrm{~mL}$ Falcon tube. The tubes were then stored at $-80^{\circ} \mathrm{C}$ prior analysis by GC-MS, which was carried out at the Department of Life and Environmental Sciences in Cagliari. After thawing on ice, the urine samples were centrifuged for 10 min at $14000 \mathrm{rpm} .150 \mu \mathrm{L}$ of surnatant from each sample was transferred into an eppendorf tube containing $1 \mathrm{mg}$ of urease, sonicated for $30 \mathrm{~min}$ at $37^{\circ} \mathrm{C}$ and then centrifuged for $10 \mathrm{~min}$ at $13200 \mathrm{rpm}$. The resulting surnatant was separated from the precipitate and dried under a gentle nitrogen stream. Dried samples were derivatized with $50 \mu \mathrm{L}$ of methoxyamine in pyridine solution $(10 \mathrm{mg} / \mathrm{mL})$. After $17 \mathrm{~h}, 100 \mu \mathrm{L}$ of BSTFA+TMCS was added and after $1 \mathrm{~h}$ samples were resuspended with $600 \mu \mathrm{L}$ of hexane. Trimethylsylilated 2, 2, 3, 3-d4-succinic acid at $5 \mathrm{mg} / \mathrm{L}$ was used as internal standard.

\subsection{GC-MS Analysis}

One microliter of derivatized sample was injected splitless into a 6850 gas chromatograph coupled with a 5973 Network mass spectrometer (Agilent Technologies, Santa Clara, CA, USA) equipped with a $30 \mathrm{~m} \times 0.25 \mathrm{~mm} \mathrm{ID}$, fused silica capillary column, which was chemically bonded with $0.25 \mu \mathrm{m}$ DB5-MS stationary phase (J\&W scientific, Folsom, CA, USA). The injector temperature was $200^{\circ} \mathrm{C}$. The gas flow rate through the column was $1 \mathrm{~mL} / \mathrm{min}$. The column initial temperature was kept at $50^{\circ} \mathrm{C}$ for $10 \mathrm{~min}$. The temperature was then increased up to $300^{\circ} \mathrm{C}$ at $10^{\circ} \mathrm{C} / \mathrm{min}$ and held at $300^{\circ} \mathrm{C}$ for $10 \mathrm{~min}$. The transfer line and the ion source temperatures were at $280^{\circ} \mathrm{C}$ and $180^{\circ} \mathrm{C}$, respectively. Ions were generated at 70 $\mathrm{eV}$ with electron ionization and were recorded at $1.6 \mathrm{scan} / \mathrm{sec}$ over the mass range $\mathrm{m} / \mathrm{z}$ 50-550. GC-MS data analysis was conducted by integrating each resolved chromatogram peak and normalizing the area for the corrected total area of the chromatogram. Peaks were examined for their mass spectra and their identification was performed using the NIST08 library after deconvolution with AMDIS.

\subsection{Multivariate Statistical Data Analysis}

Multivariate statistical data analysis of GC-MS data analysis was performed using the SIMCA software (version 13.0, Umetrics, Umea, Sweden). Untargeted principal components analysis (PCA) was applied to visualize tendency of samples to cluster based on similarities and dissimilarities in their metabolite profile and to detect the presence of outliers that may be due to errors in sample preparation or instrumentation parameters. Outliers can be detected by different tests, as implemented in SIMCA software. For sample classification and for the search of biomarkers that differentiate the predefined classes, the Orthogonal Partial Least Square-Discriminant Analysis (OPLS-DA) was performed, this is-a supervised classification method that requires information about class membership of samples. In OPLS-DA, class separation is maximized in the predictive component ( $x$-axis) and its orthogonal component ( $y$-axis) express intra-class variability. The goodness of models was evaluated by the parameters: $R^{2} Y$ (goodness of classification) and $\mathrm{Q}^{2} \mathrm{Y}$ (goodness of classification in crossvalidation). For what concerns prediction power, a permutation test was used. The study of discriminant metabolites was performed using the S-plot model, which combines covariance and correlation loading profiles [19].

\section{Results and Discussion}

A total of 28 urine samples were analyzed by GC-MS. Chromatograms and spectra analysis yield 71 metabolites from GC-MS (Table 1). 
Table 1. GC-MS characteristics of metabolites.

\begin{tabular}{|c|c|c|}
\hline Compound & Retention time (min) & EI-MS, $m / z$ (amu) (\% relative ion abundances) \\
\hline glycolic acid & 16,228 & $147-73-177$ \\
\hline alanine & 16,771 & $116-73-147$ \\
\hline glycine & 17,183 & $73-147-102$ \\
\hline oxalic acid & 17,405 & $73-147-190$ \\
\hline 3-hidroxybutiric acid & 17,884 & $147-73-233$ \\
\hline U1 & 18,224 & $73-221-248$ \\
\hline isovaleric acid & 18,733 & $73-147-131$ \\
\hline Valine & 18,815 & $73-147-144$ \\
\hline canavanine & 18,901 & $73-156-201$ \\
\hline glycine & 20,235 & $174-73-248$ \\
\hline butanedioic acid & 20,369 & $73-147-247$ \\
\hline gliceric acid & 20,552 & $73-147-187-292$ \\
\hline erithronic acid & 20,73 & $73-117-292$ \\
\hline U2 & 20,859 & $73-117-147-292$ \\
\hline serine & 20,998 & $73-204-218$ \\
\hline $\mathrm{U} 3$ & 21,208 & $73-147-117$ \\
\hline threonine & 21,332 & $73-218-291$ \\
\hline 2,4-butanoic acid & 21,695 & $73-103-147-219$ \\
\hline butanoic acid 3,4-dioh & 21,967 & $73-147-233-189$ \\
\hline homoserine & 22,206 & $73-218-128$ \\
\hline U4 & 22,245 & $73-147-350$ \\
\hline aminomalonic acid & 22,473 & $73-147-218$ \\
\hline malic acid & 22,695 & $73-147-233$ \\
\hline 1-aspartic acid & 23,107 & $73-232-218$ \\
\hline pyroglutamic acid & 23,171 & $73-156-147$ \\
\hline U5 & 23,23 & $73-129-247$ \\
\hline 2,3,4-trihidroxy butiric acid & 23,348 & $73-147-292$ \\
\hline creatinine & 23,575 & $115-73-329$ \\
\hline U6 & 23,779 & $147-129-247$ \\
\hline U7 & 24,317 & $73-147-231$ \\
\hline tartaric acid & 24,472 & $73-147-292$ \\
\hline U8 & 24,602 & $73-147-245$ \\
\hline U9 & 24,714 & $73-217-147$ \\
\hline U10 & 24,802 & $73-147-245$ \\
\hline ribose & 24,923 & $73-217-103$ \\
\hline U11 & 25,24 & $73-175-217$ \\
\hline U12 & 25,319 & $136-166-210$ \\
\hline xylitol & 25,398 & $73-217-147$ \\
\hline U13 & 25,708 & $73-217-204$ \\
\hline cis-aconitate & 25,781 & $73-147-229$ \\
\hline U14 & 25,889 & $73-357-292$ \\
\hline ribonic acid & 26,066 & $73-147-292$ \\
\hline citric acid & 26,528 & $73-147-273$ \\
\hline allo-inositol & 26,617 & $73-217-260$ \\
\hline U15 & 26,776 & $221-117-292$ \\
\hline psicose & 26,822 & $73-245-147$ \\
\hline fructose & 26,98 & $73-217-307$ \\
\hline galactose & 27,105 & $73-205-319$ \\
\hline tagatose & 27,129 & $73-217-307-103$ \\
\hline glucose & 27,183 & $73-204-147$ \\
\hline glucose & 27,229 & $73-319-205$ \\
\hline mannose & 27,289 & $217-305-321$ \\
\hline mannitol & 27,627 & $73-205-319$ \\
\hline U16 & 27,695 & $73-147-160-333$ \\
\hline U17 & 28,286 & $73-147-292$ \\
\hline gluconic acid & 28,33 & $73-147-333$ \\
\hline scyllo-inositol & 28,595 & $73-318-305$ \\
\hline palmitic acid & 28,886 & $313-75-317$ \\
\hline myo-inositol & 29,216 & $73-305-217$ \\
\hline quiric acid & 29,723 & $73-345-255$ \\
\hline oleic acid & 30,472 & 73-117-129-339 \\
\hline 2-o-glycerol-a-d-galactopyranoside & 31,165 & $73-204-217$ \\
\hline U18 & 31,400 & $73-285-222$ \\
\hline digalacturonic acid & 32,144 & $73-147-375$ \\
\hline
\end{tabular}




\begin{tabular}{lll}
\hline Compound & Retention time (min) & EI-MS, $\boldsymbol{m} / \boldsymbol{z}$ (amu) (\% relative ion abundances) \\
\hline U19 & 32,389 & $73-285-147$ \\
U20 & 32,507 & $73-375-147-254$ \\
sucrose & 33,764 & $361-73-217$ \\
lactose & 34,142 & $73-204-361$ \\
maltose & 34,56 & $73-361-217$ \\
U21 & 34,642 & $204-73-217$ \\
galactinol & 34,796 & $73-204-217$ \\
\hline
\end{tabular}

To investigate correlations between compositional and analytical data, and to observe samples distribution in the multivariate space, an unsupervised PCA analysis was performed. The first two principal components were able to describe the $35 \%$ of the total information (data not shown). No outliers were observed. With the aim to find those

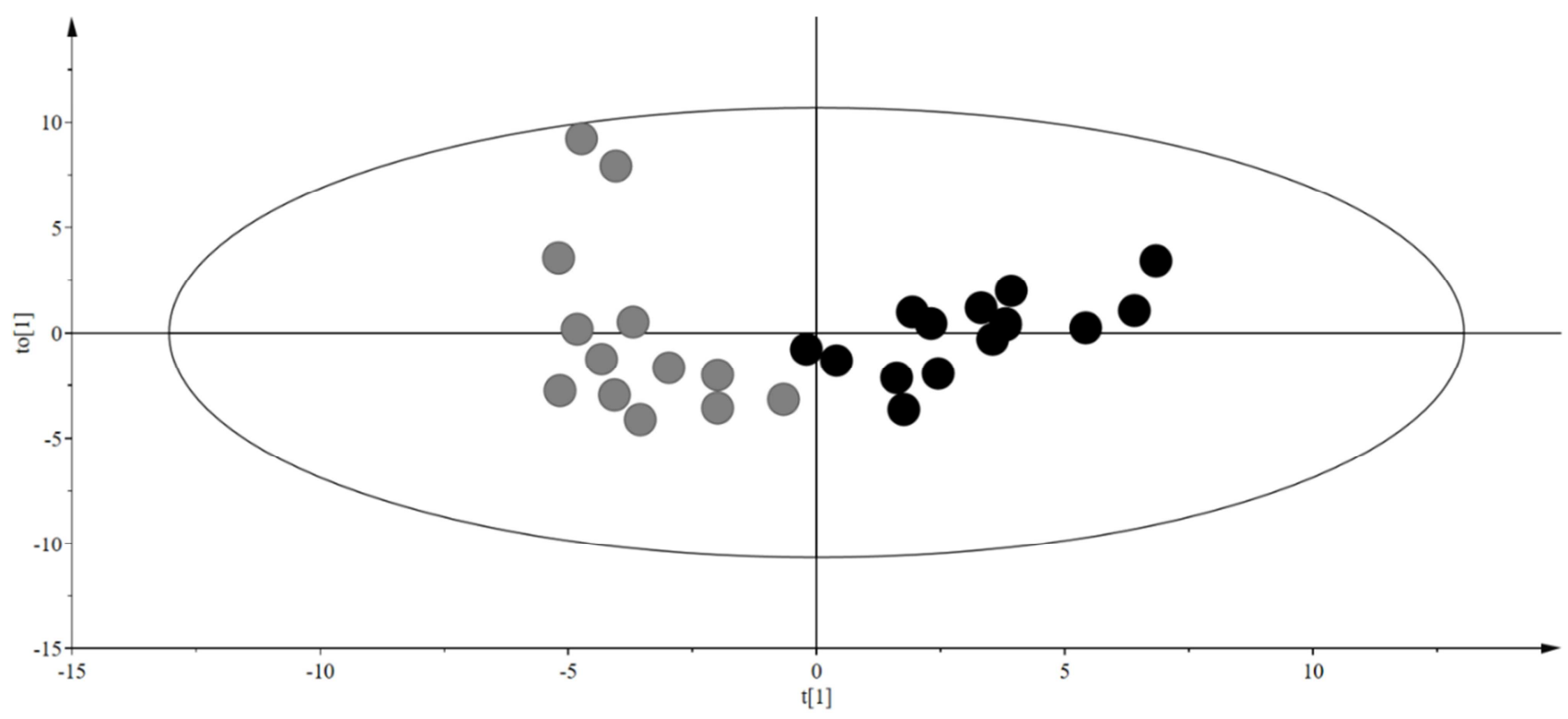

metabolites that mainly differentiate urines from patients affected by renal cell carcinoma and control samples, a supervised pair-wise OPLS-DA were applied. Validation parameters of the discriminant analysis were: 0.80 for $\mathrm{R}^{2} \mathrm{Y}$, and 0.54 for $\mathrm{Q}^{2}$ (Figure 1).

Figure 1. OPLS-DA scores plot of RCCs samples vs control samples. Validation parameters of the discriminant analysis were: 0.80 for $R^{2} Y$, and 0.54 for $Q^{2}$. Permutation test showed a $Q^{2}$ value of -0.31 .

Permutation test showed a $\mathrm{Q}^{2}$ value of -0.31 . To identify statistically significant metabolites, an S-plot was performed. The resultant most discriminant metabolites for the pathological class were: palmitic acid, malic acid, alloinositol, oleic acid, aspartic acid. The high levels of two chain fatty acids, such as palmitic acid and oleic acid, in pathological samples highlight possible alterations in the lipid metabolism. In fact, recently Hakimi el al. [20] showed an increase of fatty acid biosynthesis and a decrease in oxidative phosphorylation at the beginning of the pathogenesis and a reversal of these patterns during tumor progression. Moreover, Schieda et al. found intracellular lipid in a minority of papillary renal cell cancers [21]. Furthermore, it is still clear that lipid peroxidation, which is increased in obese and hypertensive subjects, is the mechanism responsible for their increased risk of renal cell carcinoma [22]. Furthermore, the up-regulation of malic acid in the pathological samples suggests an alteration of the citric acid cycle. In fact, different syndromes of renal cancer were recently described by Launonen et al. [23]. These syndromes evidenced a co-segregation of cutaneous leiomyomas on type II papillary renal cell carcinoma in two familiar lines that 
taking into account the need of further experiments, this study can be considered the first step towards the prediction of RCC disease.

\section{Conflict of Interest Statement}

The authors declare that there are no conflicts of interest.

Acknowledgment.

We thank Dr. Sonia Liggi for providing English language help and reading assistance.

\section{References}

[1] European Network of Cancer Registries. Eurocim version 4.0. European incidence database V2. 3, 730 entity dictionary (2001), Lyon, 2001.

[2] Lindblad P. Epidemiology of renal cell carcinoma. Scand J Surg. 2004; 93: 88.

[3] Eble JN, Sauter G, Epstein JI (eds). In: Pathology and genetics of tumours of the urinary system and male genital organs. World Health Organization Classification of Tumours. Lyon: IARC Press, 2004.

[4] Srigley JR, Delahunt B, Eble JN, Egevad L, Epstein, JI, Grignon D et al. The International Society of Urological Pathology (ISUP) vancouver classification of renal neoplasia. The American journal of surgical pathology. 2013; 37(10): 1469-1489.

[5] Furge KA, Tan MH, Dykema K, Kort E, Stadler W, Yao X, et al. Identification of deregulated oncogenic pathways in renal cell carcinoma: an integrated oncogenomic approach based on gene expression profiling. Oncogene. 2007; 26: 1346.

[6] Novara G, Ficarra V, Antonelli A, Artibani W, Bertini R, Carini M, et al. Validation of the 2009 TNM version in a large multi-institutional cohort of patients treated for renal cell carcinoma: are further improvements needed? EurUrol. 2010; 58: 588 .

[7] Jayson M, \& Sanders H. Increased incidence of serendipitously discovered renal cell carcinoma. Urology. 1998; 51: 203.

[8] Hammers, H., Sternberg, C., Mcdermott, D. F., Larkin, J., Ravaud, A., Rini, B., A Phase 3, Randomized, Open-Label Study of Nivolumab Combined With Ipilimumab Versus SunitinibMonotherapy in Subjects With Previously Untreated, Advanced or Metastatic Renal Cell Carcinoma. 2015; p. NCT02231749.

[9] Sim SH, Messenger MP, Gregory WM, Wind TC, Vasudev NS, Cartledge J, et al. Prognostic utility of pre-operative circulating osteopontin, carbonic anhydrase IX and CRP in renal cell carcinoma. Br J Cancer. 2012; 107: 1131.

[10] Sabatino M, Kim-Schulze S, Panelli MC, Stroncek D, Wang E, Taback B, et al. Serum vascular endothelial growth factor and fibronectin predict clinical response to high-dose interleukin-2 therapy. J ClinOncol. 2009; 27: 2645.

[11] Li G, Feng G, Gentil-Perret A, Genin C, Tostain J. Serum carbonic anhydrase 9 level is associated with postoperative recurrence of conventional renal cell cancer. J Urol. 2008; 180: 510

[12] Choueiri TK, Pal SK, McDermott DF, Morrissey S, Ferguson KC, Holland J, et al. A phase I study of cabozantinib (XL184) in patients with renal cell cancer. Ann Oncol. 2014; 25: 1603.

[13] Choueiri TK, Escudier B, Powles T, Mainwaring PN, Rini BI, Donskov F, et al. Cabozantinib versus Everolimus in Advanced Renal-Cell Carcinoma. N Engl J Med. 2015; 373: 1814.

[14] Motzer RJ, Escudier B, McDermott DF, George S, Hammers HJ, Srinivas S, et al. Nivolumab versus Everolimus in Advanced Renal-Cell Carcinoma. N Engl J Med. 2015; 373: 1803.

[15] Wahlgren $T$, Harmenberg U, Sandström $P$, Lundstam $S$, Kowalski J, Jakobsson, M, et al. Treatment and overall survival in renal cell carcinoma: a Swedish population-based study (2000-2008). Br J Cancer. 2013; 108: 1541.

[16] Scano P, Murgia A, Pirisi F. M, Caboni P. A gas chromatography-mass spectrometry-based metabolomic approach for the characterization of goat milk compared with cow milk. J Dairy Sci. 2014; 97(10): 6057-6066.

[17] Pisano MB, Scano P, Murgia A, Cosentino S, Caboni P. Metabolomics and microbiological profile of Italian mozzarella cheese produced with buffalo and cow milk. Food Chem. 2016; 192: 618-624.

[18] Dessì A, Murgia A, Agostino R, Pattumelli MG, Schirru A, Scano P, et al. Exploring the Role of Different Neonatal Nutrition Regimens during the First Week of Life by Urinary GC-MS Metabolomics. Int. J. Mol. Sci. 2016; 17(2): 265.

[19] Eriksson L, Byrne T, Johansson E, Trygg J, Vikström C. Multi-and megavariate data analysis basic principles and applications. 2013; Umetrics Academy.

[20] Hakimi AA, Reznik E, Lee CH, Creighton CJ, Brannon AR, Luna A. An Integrated Metabolic Atlas of Clear Cell Renal Cell. Cancer cell. 2016; 29(1): 104-116.

[21] Schieda N, Van der Pol CB, Moosavi B, McInnes MD, Mai KT, Flood TA. Intracellular lipid in papillary renal cell carcinoma (pRCC): T2 weighted (T2W) MRI and pathologic correlation. European radiology. 2015; 25(7): 2134-2142.

[22] Gago-Dominguez M, Castelao JE, Yuan JM, Ross RK, Mimi CY. Lipid peroxidation: a novel and unifying concept of the etiology of renal cell carcinoma (United States). Cancer Causes \& Control. 2002; 13(3): 287-293.

[23] Launonen V, Vierimaa O, Kiuru M, Isola J, Roth S, Pukkala E, et al. Inherited susceptibility to uterine leiomyomas and renal cell cancer. Proceedings of the National Academy of Sciences. 2001; 98(6): 3387-3392.

[24] Ooi A, Furge KA. Fumarate hydratase inactivation in renal tumors: HIF1 $\alpha$, NRF2, and "cryptic targets" of transcription factors. Chinese journal of cancer. 2012; 31(9): 413.

[25] Tan J, Yu CY, Wang ZH, Chen HY, Guan J, Chen YX, et al. Genetic variants in the inositol phosphate metabolism pathway and risk of different types of cancer. Scientific reports. 2015; 5: 8473 . 